\title{
Electrospun Fibers Immobilized with BMP-2 Mediated by Polydopamine Combined with Autogenous Tendon to Repair Developmental Dysplasia of the Hip in a Porcine Model
}

This article was published in the following Dove Press journal:

International Journal of Nanomedicine

\section{Ruiqi Wu* \\ Guanying Gao* \\ Yan Xu}

Department of Sports Medicine, Peking University Third Hospital, Beijing,

People's Republic of China

*These authors contributed equally to this work
Correspondence: $Y a n \mathrm{Xu}$

Tel +86 I370I I3040 I

Email yanxu@।39.com
Purpose: Developmental dysplasia of the hip (DDH) can increase the pressure between the joints, which causes secondary hip osteoarthritis. The aim of the present study was to fabricate poly(D, L-lactic acid)-poly(ethylene glycol)-poly(D, L-lactic acid) (PELA) electrospun fibrous scaffolds, immobilized with bone morphogenetic protein-2 (BMP-2), to repair the acetabulum defects.

Methods: The characteristics of PELA electrospun were analyzed using scanning electron microscopy, the release kinetics of BMP-2 in vitro were analyzed using enzyme-linked immunosorbent assays. Human mesenchymal stem cells (hMSCs) were used for in vitro experiments, the biocompatibility of the electrospinning materials was investigated using a cell counting kit-8 (CCK-8) kit, and osteogenic differentiation was tested via alkaline phosphatase (ALP) activity and relative gene expression. Eighteen miniature pig animal models were used in the in vivo experiment. The pigs were sacrificed at 24 weeks after surgery, and the reconstructed acetabulum was evaluated using histological sections.

Results: Structural analysis revealed that the diameter of the PELA electrospun fiber was $0.8195 \pm 0.16 \mu \mathrm{m}$. The PELA electrospun fiber materials showed good hydrophilicity and biocompatibility and could continuously release BMP- 2 within 27 days: $16.07 \pm 0.11 \mathrm{ng}$ of BMP-2 was released from the scaffold. A total of sixteen implants fully filled the defects, and hematoxylin and eosin staining and Goldner's trichrome staining showed that the simple tendon group ( $\mathrm{T}$ group) was mostly fibrous tissues, lots of fibroblasts and small amounts of chondrocytes were observed in the polydopamine-coated electrospun fiber group (DP group). The DP plus BMP-2 (DPB) group showed a large number of chondrocytes and partial new bone tissues.

Conclusion: PELA electrospun fibrous scaffolds are good sustained-release carriers, which can not only induce implant differentiation into cartilage and bone but also are completely degraded without toxicity. Therefore, the material can be used for bone and cartilage regeneration.

Keywords: electrospun fibers, acetabulum reconstruction, bone marrow stem cells, osteogenic growth factor

\section{Introduction}

Developmental dysplasia of the hip (DDH) is a common hip disease. The abnormal coverage of the femoral head by the acetabulum increases the pressure between the joints, often resulting in secondary osteoarthritis $(\mathrm{OA}) .^{1,2}$ If not treated in time, early 
hip subluxation or total dislocation might result in severe dysfunction in the advanced stage. The incidence of acetabular dysplasia is related to factors such as race, region, and fetal development. ${ }^{3,4}$ The incidence of acetabular dysplasia is about $0.7 \%,{ }^{5}$ and is more common in women than in men. The incidence of secondary OA in DDH is as high as $43 \%$ to $79 \%{ }^{6}$ Once a degenerative lesion occurs, it is difficult to cure and the prognosis is poor. Therefore, early detection and treatment of DDH, which could delay or even prevent progression to hip osteoarthritis, are critical.

DDH can be treated conservatively and surgically; however, conservative treatment cannot allow a complete cure because of abnormalities of the acetabular anatomy. Patients with clinical symptoms are usually treated with surgery. The main surgical methods include acetabular osteotomy, hip arthroplasty, and acetabular capping. Early osteotomy might delay the progression of osteoarthritis to some extent, and delay or avoid hip arthroplasty; however, there are some shortcomings, such as heterotopic ossification and reductions in the range of movement, which could also affect a women's future delivery of her neonate. ${ }^{7,8}$

Hip arthroscopy has developed rapidly in recent years, providing a new mini-invasive therapy for DDH. As a classic procedure, acetabular capping can avoid a series of problems caused by osteotomy, especially for patients with a shallow acetabulum, without obvious deformation of the femoral head. However, this procedure usually requires extraction and grafting of bone, and there are defects such as bleeding, infection, and limited bone extraction. If a tissue-engineered acetabulum can be constructed, then the minimally invasive method of "acetabular capping" can greatly reduce the surgical trauma and overcome these defects.

Seed cells, growth factors, and biological materials are the three major elements in tissue engineering. Mesenchymal stem cells (MSC) are increasingly used in bone and cartilage regeneration because of their easy separation, high amplification rate, low immunogenicity, and pluripotency, making them preferred seed cells in clinical research. ${ }^{9}$ Bone marrow mesenchymal stem cells (BMSCs) can differentiate into osteoblasts, chondrocytes, adipocytes, and even myoblasts. In addition, BMSCs combined with scaffolds can repair damaged tissue. ${ }^{10}$ BMSCs are now widely used as seed cells for tissue engineering, cell therapy, and regenerative medicine because of their multipotential differentiation, selfrenewal, immune regulation, and other effects. ${ }^{11}$

Bone morphogenetic proteins (BMPs) are extracted from bone tissue, and to date, more than 40 species have been discovered. Bauge et $\mathrm{al}^{12}$ confirmed that BMPs are essential signaling molecules for embryonic development and postnatal organ development, which can induce MSCs to undergo osteogenesis and differentiate into chondrocytes. Among them, BMP-2 has been extensively studied for its important role in osteogenesis. Clinical trials have confirmed the efficacy of FDA-approved recombinant human BMP-2 and BMP-7. ${ }^{13}$ However, the release of BMPs is not controlled, which leads to local soft-tissue edema, hematoma, heterotopic ossification, and other complications, thus more account of its safety needs to be taken. ${ }^{14,15}$ Therefore, whether BMP-2 can be released in a controlled manner is the key factor.

In recent years, electrospun fibers have been widely used in tissue engineering. An electrospun fiber is filmlike and has certain flexibility and convenience in the production process. It stimulates the structure of the extracellular matrix (ECM). A large number of tissue engineering techniques are based on electrospinning. ${ }^{16,17}$ Electrospun material has a large surface area, which provides special surface characteristics (such as surface topology and surface energy) ${ }^{18}$ therefore, it has been developed as a material to promote tissue regeneration. In the previous research, Kutikov et al developed poly(D, L-lactic acid)-co-poly(ethylene glycol)-co-poly(D, L-lactic acid) (PELA) via electrospinning and applied it in research into bone regeneration. The hydrophilic poly- (ethylene glycol) (PEG) has favorable hydrophilic properties, while the hydrophobic poly $(\mathrm{D}$, L-lactic acid) (PLA) blocks provide biodegradability and aqueous stability. ${ }^{19,20}$ Moreover, PELA electrospun fibers are more flexible and easier to use than other commonly used material (eg, PLA). PELA is also effective for drug delivery applications. ${ }^{21}$ Polydopamine has been used as a crosslinker, which can tightly bind to various surfaces via covalent and non-covalent interactions, and could serve as an intermediate for the conjugation of biomolecules onto scaffold surfaces with low toxicity. ${ }^{22}$ Previous studies have shown that polydopamine had a similar composition to mussel adhesive pads, which provide strong adhesion to any type of material surface. ${ }^{23,24}$ Therefore, electrospinning technology can control the morphology and porosity of the polymer biological production, and BMP-2 can be cross-linked on the electrospun fibrous scaffold to achieve controlled release and ossification. In our previous research, ${ }^{25}$ we constructed a coaxial electrospun fibrous scaffold, which provide a good spatial environment for chondrogenic differentiation of stem cells. Therefore, we aimed to use PELA electrospun fibers as the scaffold, polydopamine as a cross-linking agent to coat the surface of the scaffold (Figure 1A), and then immobilize BMP-2 to achieve a controlled release (Figure 


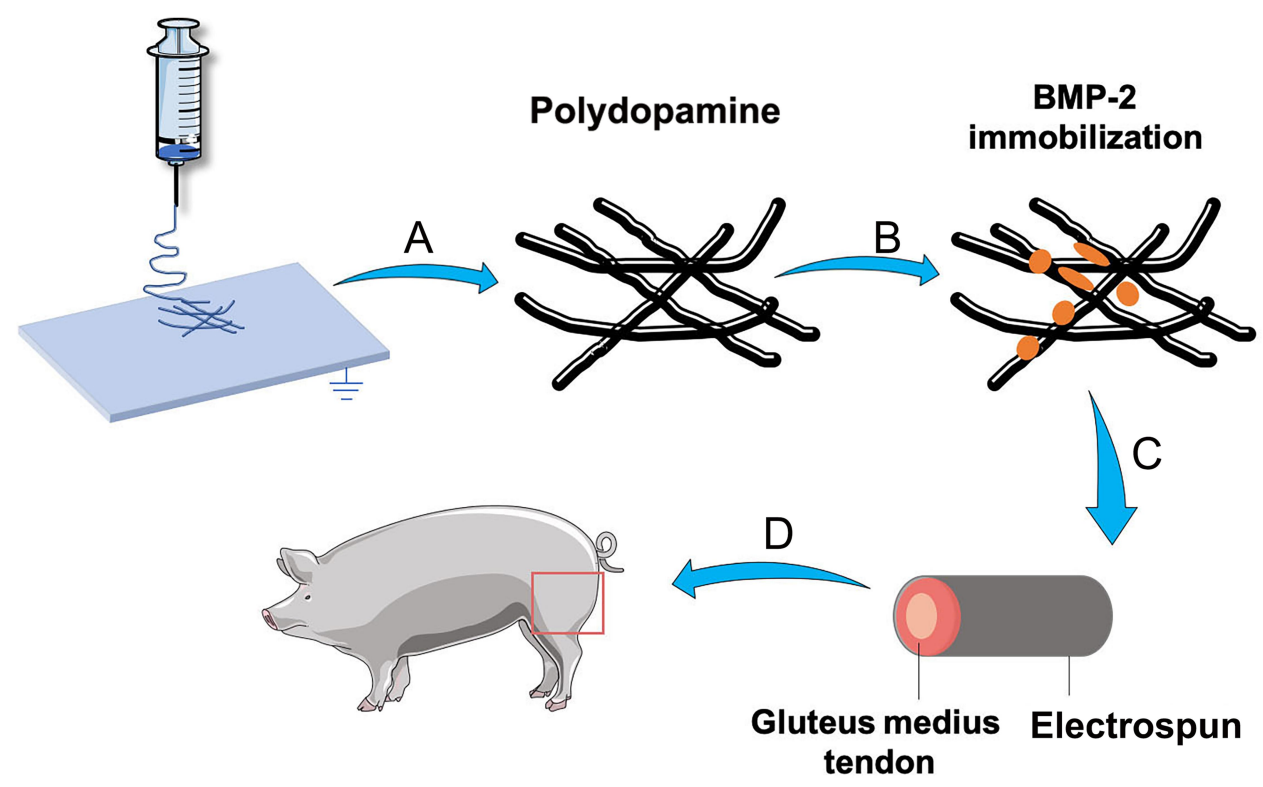

Figure I Scheme of the electrospinning process and the reconstruction of the acetabulum. (A) Electrospun fiber with polydopamine coating; (B) Electrospun fibers with immobilized BMP-2; (C) Electrospun fibers wrapping the gluteus medius tendon to make implant; (D) The implant repaired the acetabular defect. Notes: Figure I is produced using Servier Medical Art (https://smart.servier.com/). Creative Commons Attribution 3.0 Unported (CC BY 3.0). ${ }^{38}$

1B). We then wrapped the gluteus medius tendon with electrospun fiber to repair the acetabular defect in a porcine model (Figure 1C and D). We hypothesized that BMPmodified electrospun fibrous scaffolds wrapped around an autogenous tendon would promote osteogenesis and replace autologous bone to complete acetabular capping. Figure 1 is produced using Servier Medical Art.

\section{Materials and Methods Preparation of PELA Electrospun Fibers} First, 0.5 g poly(D, L-lactic acid)-poly(ethylene glycol)-poly (D, L-lactic acid) (PELA) (MPEG5000, Bioruler, Beijing, China) $(\mathrm{Mw}=40 \mathrm{kDa}, \mathrm{E} / \mathrm{L}=10 / 90, \mathrm{Mw} / \mathrm{Mn}=1.56)$ was completely dissolved in a solvent containing 1.5 g dichloromethane (DCM) (T_701AA39116AP, Thermo Fisher Scientific, Rockford, IL, USA) and 0.8 g dimethylformamide (DMF) (GEN002007, Thermo Fisher Scientific) to prepare PELA electrospun scaffolds. The mixture was stirred overnight at room temperature and loaded into a $1 \mathrm{~mL}$ syringe. A high voltage power supply delivered an 8 $\mathrm{kV}$ voltage difference between the needle tip and an aluminum collection plate set at $10 \mathrm{~cm}$ distance. The polymer solution was fed through the needle at a rate of $1.7 \mathrm{~mL} / \mathrm{h}$ using a syringe pump, and the fibers were collected on the aluminum collector plate. The scaffolds were dried in a vacuum oven at room temperature for $48 \mathrm{~h}$ to remove any residual solvent and stored in a desiccator at $4^{\circ} \mathrm{C}$.

\section{Immobilization of BMP-2}

The immobilization of BMP-2 on the electrospun fibers was performed according to the method of Hyeong-jin Cho, with some modifications. ${ }^{26}$ Briefly, Dopamine was dissolved in Tris-buffer solution ( $\mathrm{pH}$ 8.5) at a concentration of $2 \mathrm{mg} / \mathrm{mL}$. A $2 \mathrm{~cm}$-diameter electrospun fiber was immersed in the solution, a rotor pressed on the electrospun fiber to prevent it from floating, and then the solution was stirred at $50 \mathrm{rpm}$ on an orbital shaker overnight. The fiber was rinsed several times with deionized water and stirred for $4 \mathrm{~h}$ to remove un-crosslinked dopamine. Then, each side of the treated electrospun fibers was sterilized under ultraviolet light (the wavelengths of the UV lamp were $254 \mathrm{~nm}$ and $365 \mathrm{~nm}$ ) within a 20-cm distance for $2 \mathrm{~h}$ before use. The electrospun fiber was soaked in $1 \mathrm{~mL}$ of $500 \mathrm{ng} / \mathrm{mL}$ BMP-2 solution, crosslinked at $37^{\circ} \mathrm{C}$ overnight, and transferred to fresh phosphatebuffered saline (PBS, pH 7.4) solution the next day.

\section{Characteristics of the Electrospun Materials}

The surface morphology of electrospun fibers was examined using an S-4800 scanning electron microscope (SEM). The diameters of the fibers were measured using Image-Pro Plus 6.0 software (Media Cybernetics, Bethesda, MD, USA) and 30 counts were performed for each scaffold. 


\section{The Release Characteristic of BMP-2}

Electrospun fibers with a diameter of $2 \mathrm{~cm}$ were transferred to fresh PBS solution the next day. The supernatant was collected on days $1,3,5,7,10,15,21$, and 30 , respectively, while adding $1 \mathrm{~mL}$ fresh PBS solution each day. The collected liquid was placed in a $-80^{\circ} \mathrm{C}$ freezer and tested on the 30th day. The release of BMP-2 was determined using a BMP-2 ELISA kit (ab119582; Abcam, Cambridge, MA, USA).

\section{hMSCs Culture and Seeding on the Scaffolds}

Human bone marrow-derived mesenchymal stem cells (hMSCs) (HUXMA-01001; Cyagen Biosciences, Guangzhou, China) were used in the in vitro experiments. Briefly, cells were cultivated with Dulbecco's modified Eagle's medium (DMEM) containing 10\% fetal bovine serum (FBS; SV30087.03, Hyclone, Logan, Utah, USA), grew on $10 \mathrm{~cm}$-diameter dishes and maintained at $37^{\circ} \mathrm{C}$, in a 5\% carbon dioxide incubator. The medium in the dishes was renewed every other day until the cells reached confluency. Third-passage hMSCs were used for the study. Three kinds of scaffolds were used in the in vitro experiment, including PELA electrospun fiber (P), polydopaminecoated electrospun fiber (DP), and polydopamine-coated electrospun fiber immobilized with $500 \mathrm{ng} / \mathrm{mL}$ BMP-2 (DPB). Electrospun fibrous scaffolds were punched into two-cm diameter discs, after which they were placed in a UV-sterilized six-well plate. The cells were removed from the culture dishes using trypsin-EDTA, and then the hMSCs were seeded onto P, DP, and DPB scaffolds at a density of $4 \times 10^{5}$ cells per well. Firstly, $100 \mu \mathrm{L}$ of cell suspension was added to each side, and the after $30 \mathrm{~min}$, when the cells had attached to the scaffolds, $2 \mathrm{~mL}$ of medium was added. Twenty-four hours later, the medium was changed to hMSCs osteogenic induction medium (HUXMA-90021; Cyagen Biosciences) for the following experiments.

\section{The Growth and Attachment of the hMSCs}

Attachment of the cells was observed using scanning electron microscopy. The cells were seeded on a scaffold and observed on day 7 . Then, the scaffolds were rinsed with PBS, and the sample was fixed with $2.5 \%$ pentane. The sample was dehydrated with ethanol and gold-coated then observed under the SEM.

\section{The Biocompatibility of Material and Cytotoxicity}

The biocompatibility of the materials was tested using Live \& dead staining. Briefly, after the cells were seeded on the scaffolds and cultured for 7 days, the samples were washed once with PBS, and then calcein-AM and Ethidium homodimer-1 (EthD-1) (L6023, US Everbright, Suzhou, China) were mixed into a working solution of $6 \mu \mathrm{M}$, and added to the sample. The samples were incubated for $30 \mathrm{~min}$ in the dark, and then the samples were observed using confocal microscopy (CFM). Cytotoxicity was assessed using a cell counting kit-8 (CCK-8) (CK04, DOJINDO, Shanghai, China). The $6 \mathrm{~mm}$-diameter scaffolds were sterilized under UV for $2 \mathrm{hrs,} \mathrm{and} \mathrm{then} \mathrm{placed}$ on 96-well plate. Briefly, the cells were seeded on electrospun fiber and cultured for $24 \mathrm{hrs}, 3$ days, and 7 days. At each time point, $10 \mu \mathrm{L}$ of $\mathrm{CCK}-8$ reagent was added to each well. After incubating for $2 \mathrm{hrs}$ in a $37^{\circ} \mathrm{C}$ incubator, $100 \mu \mathrm{L}$ of the supernatant was pipetted into a 96-well plate, and the absorbance at $450 \mathrm{~nm}$ was measured using a microplate reader (Thermo Fisher Scientific, Rockford, IL, USA).

\section{The Assay of Osteogenic Differentiation for hMSCs Cultured on Scaffolds}

To detect the osteogenic differentiation of hMSCs, alkaline phosphatase (ALP) activity and bicinchoninic acid (BCA) protein quantification were measured, to verify the biological activity of BMP-2 was retained on the scaffold. Briefly, we prepared $2 \mathrm{~cm}$-diameter electrospun fibrous scaffolds, placed them on the bottom of a six-well plate, and hMSCs were seeded on the three kinds of treated scaffolds (P, DP, DPB). After 7 and 14 days, $150 \mu \mathrm{L}$ of Radioimmunoprecipitation assay (RIPA) cell lysis buffer (P0013B, Beyotime Institute of Biotechnology, Beijing, China) was added to each well to treat the cells on the scaffolds. The scaffold was divided into small pieces and the supernatant was collected by centrifugation at 13,000 $\times$ $g$ for 10 min. The BCA kit (P1511, Applygen, Beijing, China) was used to determine the protein content according to the manufacturer's instructions. Briefly, $25 \mu \mathrm{L}$ of sample was added with $200 \mu \mathrm{L}$ of working solution. The working solution was prepared by mixing $5 \mathrm{~mL}$ of BCA Reagent with $100 \mu \mathrm{L}$ of $\mathrm{Cu}$ Reagent. After incubating at $37^{\circ} \mathrm{C}$ for 30 mins, the absorbance was measured at 562 $\mathrm{nm}$. Using an ALP kit (P0321, Beyotime Institute of Biotechnology) to measure ALP activity, $50 \mu \mathrm{L}$ 
p-nitrophenyl phosphate was added to $50 \mu \mathrm{L}$ of supernatant, and then the mixture was incubated at $37^{\circ} \mathrm{C}$ for 30 mins. Then, $100 \mu \mathrm{L}$ of stop solution was added to stop the reaction, and the absorbance was measured at $405 \mathrm{~nm}$. The relative activity of ALP was measured by the ratio of ALP activity to the protein concentration performed by BCA protein quantification.

After 7 and 14 days of incubation in each scaffold, qRTPCR was performed to detect the relative gene expression of $A L P, B M P 2$, and COL1. GAPDH (glyceraldehyde 3-phosphate dehydrogenase) was used as a reference gene control. The relative change of gene expression was calculated using the $2^{\Delta \Delta \mathrm{Ct}}$ method.

The PCR primers were as follows:

human $A L P$

forward: ACTGGTACTCAGACAACGAGAT

reverse: ACGTCAATGTCCCTGATGTTATG

human $B M P 2$

forward: ACCCGCTGTCTTCTAGCGT

reverse: TTTCAGGCCGAACATGCTGAG

human COL1

forward: GAGGGCCAAGACGAAGACATC

reverse: CAGATCACGTCATCGCACAAC

human $G A P D H$

forward: GCACCGTCAAGGCTGAGAAC

reverse: TGGTGAAGACGCCAGTGGA

All tests were performed in triplicate.

\section{Animal Model and Surgery}

The experimental protocols involving animals were approved by the Animal Care and Use Committee of Peking University Third Hospital (project number: A2018008), and carried out according to the "Guide for the Care and Use of Laboratory Animals" published by the National Academy Press (NIH Publication No. 85-23, revised 1996). The laboratory animals were handled according to animal welfare and international practice and the $3 \mathrm{R}$ principles (reduction, refinement, and replacement). Eighteen mature male Chinese experimental miniature pigs, with a weight range of $25-30 \mathrm{~kg}$, were used in the in vivo experiment. The animals were randomly divided into three groups, including a simple tendon group ( $\mathrm{T}$ group, $\mathrm{n}=6$ ), polydopamine-coated electrospun fiber group (DP group, $\mathrm{n}=6$ ) and polydopamine-coated electrospun fiber immobilized with $1 \mu \mathrm{g} / \mathrm{mL}$ BMP-2 group (DPB group, $n=6$ ). The experiment was performed on one side and the control on the other side.

The pigs were anesthetized with propofol in the animal laboratory. The $1 \mathrm{~cm}$ long and $5 \mathrm{~mm}$ wide gluteus medius tendon was removed. The electrospun fiber was trimmed to $2 \times 2 \mathrm{~cm}$ size, and the tendons were wrapped into DP or DPB scaffolds and braided with 2-0 non-absorbable sutures (Figure 2A and B). A Rongeur was used to make acetabular defects (Figure 2C). The implant was then transplanted into the acetabulum defect and fixed using $2.8 \mathrm{~mm}$ suture anchors (Smith \& Nephew, USA). Finally, the capsule, soft tissue, and skin were closed using 3-0 non-absorbable sutures (Figure 2D). Each animal was kept in a single cage to prevent postoperative infection. Five days after the operation, antibiotics (500 mg/day) were continuously injected. The pigs were sacrificed by over-anaesthetizing at 24 weeks after surgery.

\section{Histological Analysis}

The samples were fixed with 4\% paraformaldehyde for 24 hrs, decalcified with decalcifying solution, and the supernatant was replaced every 2 days. After dehydration, the samples were embedded in paraffin. The sample was cut into $5-\mu \mathrm{m}$ sections. The sections were dewaxed and stained with hematoxylin and eosin (H\&E), and osteogenesis of the tissues was observed by staining with Goldner's trichrome (G3550, Solarbio, Beijing, China).

\section{Statistical Analysis}

The data were expressed as the mean \pm standard deviation, using GraphPad Prism 8.0 software (GraphPad Inc, La Jolla, CA, USA). The results of diameter distribution and ALP activity were analyzed using one-way analysis of variance (ANOVA); CCK-8 and gene relative expression data were analyzed using two-way ANOVA with multiple comparisons; $\mathrm{p}<0.05$ was considered statistically significant. Histology was analyzed according to the different groups. All experiments were performed at least three times.

\section{Results}

\section{Physicochemical Characteristics of the Electrospun Fibers}

Previous studies have shown that PLA, PLLA, and PLGA electrospun fibers had good degradation abilities and mechanical properties. ${ }^{16,27-29}$ In this study, PELA scaffolds were cross-linked to BMP-2 with polydopamine and used for osteogenesis induction. The experimental group included P, DP, and DPB groups.

We observed the different electrospun fibers under an electron microscope (Figure 3A-C) and measured their diameters (Figure 3D-F). The fiber diameters of the P, DP, and 

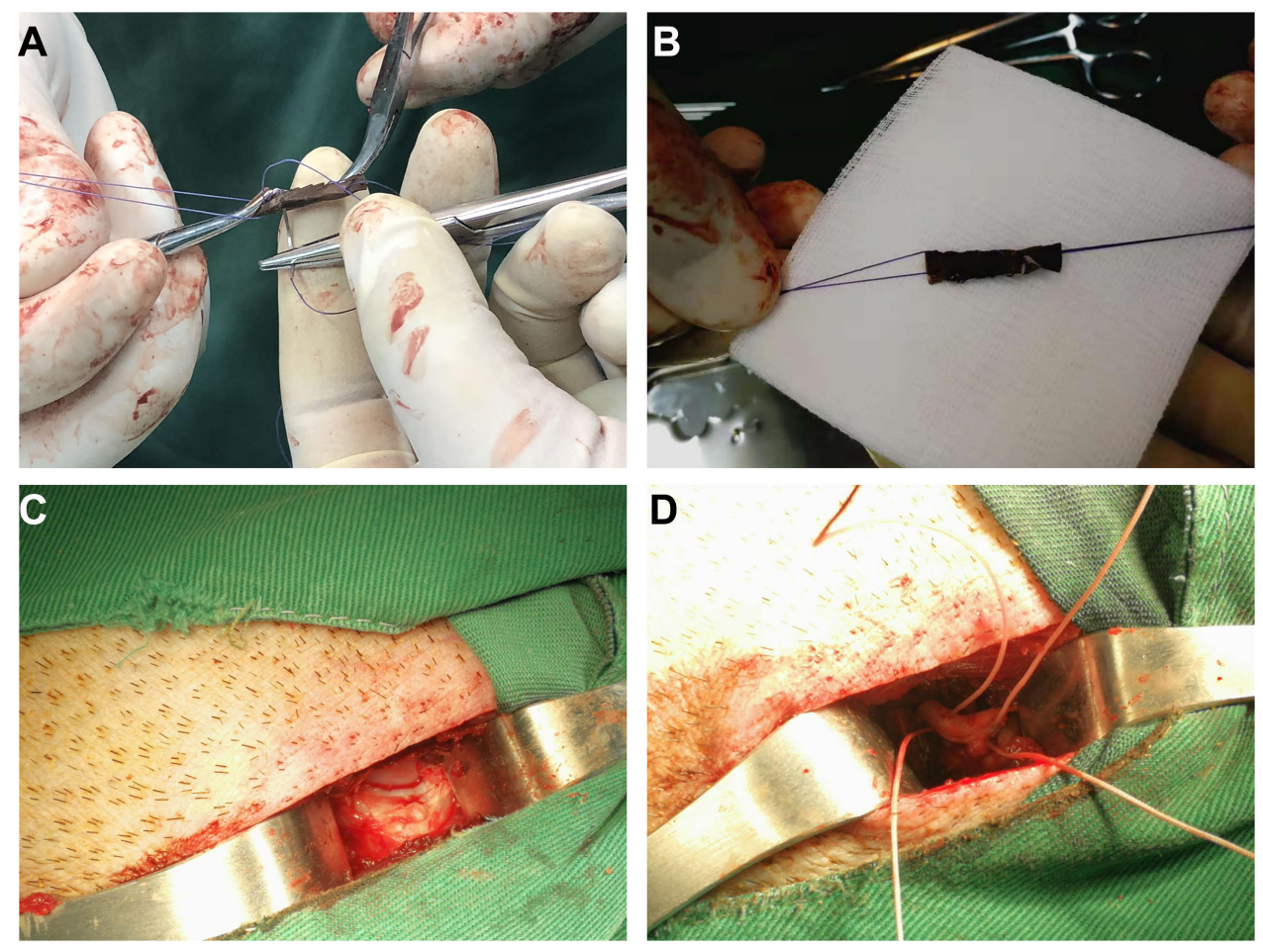

Figure 2 The acetabulum surgery in a porcine model. (A) Electrospun fibrous scaffold-wrapped autologous gluteus medius; (B) The implant was made with a tendon and scaffold; (C) An acetabular defect was induced; (D) The process of fixing the implant to the acetabulum.

DPB scaffold were $0.8195 \pm 0.16,1.311 \pm 0.3784$, and $1.411 \pm$ $0.2969 \mu \mathrm{m}$, respectively. The mean fiber diameter of the scaffolds was $1.223 \pm 0.4784 \mu \mathrm{m}$. There were no significant differences in the diameters of the electrospun fibers between the DP and DPB groups; however, the diameter of the P group was smaller than the others $(\mathrm{P}<0.05)$. Thus, the dopamine coating increased the diameter of the fiber (Figure $3 \mathrm{G}$ ). Previous studies have also used polydopamine to cross-link affinity peptides in scaffolds, and they also found that the diameter increased, further illustrating that polydopamine was successfully cross-linked, with no significant effect on the attachment and growth of cells. ${ }^{30}$

\section{The Release of BMP-2 from Electrospun Fibers}

The release of BMP-2 from the electrospun fibers was tested using an ELISA kit. As shown in Figure 4, BMP2 was continuously and slowly released within 27 days, with $16.07 \pm 0.11 \mathrm{ng}$ of BMP-2 being released from the DPB scaffold over 27 days. We observed that approximately $96.78 \%$ of the BMP-2 was immobilized on the electrospun fibers, and about $3.2 \%$ of the BMP-2 continued to be released. The result shows that most of BMP-2 was stably retained on the electrospun fibers.

\section{hMSCs Grow on Electrospun Fibers}

The cell morphology of hMSCs cultured on the electrospun fibers was characterized by scanning electron microscopy. We seeded hMSCs on three types of electrospun fibers, $\mathrm{P}$, DP, and DPB, and cultivated them for 7 days. hMSCs were grown on three scaffolds using the same culture conditions. Limited cell adhesion and spreading were observed in the $P$ group at after 7 days of cultivation (Figure $5 \mathrm{~A}$ and $\mathrm{D}$ ). The number of attached cells in DPB group was less than that in the DP group (Figure 5C and F). Besides, there was stable cell attachment and growth in the DP group at 7 days (Figure 5B and E), which was mostly consistent with previous studies, which showed improved cell recruitment in polydopamine coating scaffolds. $^{26,29}$

\section{The Biocompatibility of Electrospun Fiber and Cytotoxicity}

The biocompatibility was assessed by Live \& Dead staining, as shown in Figure 6. hMSCs were seeded on the material and cultivated for 7 days. Fluorescence CFM images of live and dead cells showed that most cells were stained green, indicating that most hMSCs were viable on all scaffolds. The morphology and size of the cells were normal, and no 

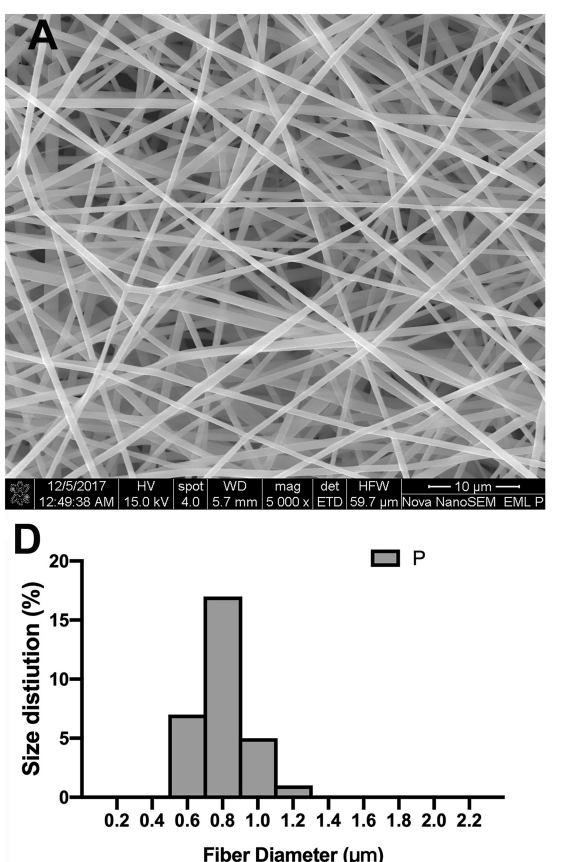

Fiber Diameter $(\mu \mathrm{m})$

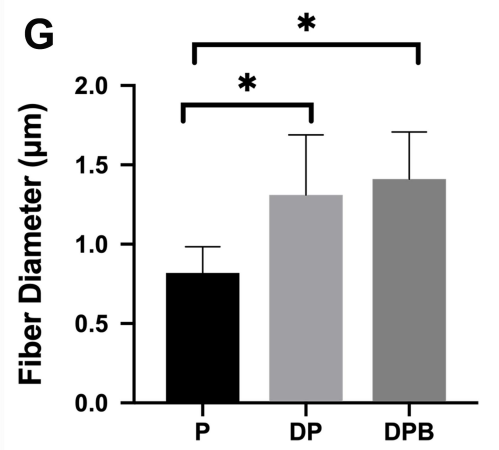

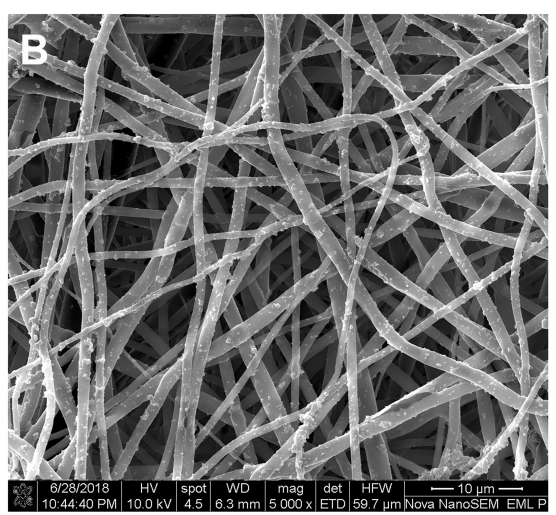

E

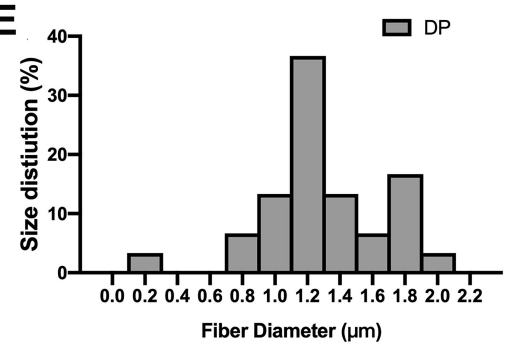



$\mathbf{F}$



Figure 3 Characteristics of electrospun fibrous scaffolds. (A) PELA scaffold, (B) DP scaffold, (C) DPB scaffold, (D) Diameter distribution of P, (E) Diameter distribution of DP, (F) Diameter distribution of DPB, (G) The comparison of fiber diameters. Scale bar $=10 \mu \mathrm{m}$. (*Statistically significant, $\mathrm{P}<0.05)$.

obvious cytotoxicity was observed. Especially in the DP and DPB group, the cells were already overgrown on the electrospun fiber after 7 days. Polydopamine could improve the hydrophilicity of the material, which was conducive to cell attachment (Figure 6A-C).

Cytotoxicity was detected using the CCK-8 kit at each time point. At $24 \mathrm{~h}, 48 \mathrm{~h}$, and 7 days after cell seeding, the CCK-8 results showed that cell proliferation was slower in the DPB and DP group, compared with that in the P group and control group at $24 \mathrm{~h}$ and $48 \mathrm{~h}$; there was no significant difference among four groups after 7 days (Figure 6D). The reason might be that cell adhesion and growth were relatively slow in the early stage of culture, and the cells underwent a certain adaptation process to the growth environment containing polydopamine; thereafter, proliferation was accelerated at the later stage.

\section{Osteogenic Differentiation of hMSCs on Different Scaffolds}

HMSCs grew well on DPB, without significant cytotoxicity. Therefore, the osteogenic induction ability of the material was further tested. ALP activity measurement and BCA protein quantification were performed on day 7. As shown in Figure 7A, after 7 days of culture, the ALP activity in the DPB group was significantly higher than that in the control and relatively higher than that in the DP group; there was no significant difference between the DP group and the control group.

The results of qRT-PCR showed that $A L P$ was expressed at a higher level in the DPB group than in the DP and control group, after 7 and 14 days of incubation (Figure 7B), which were consistent with the results for ALP activity and the protein levels. The expression of 


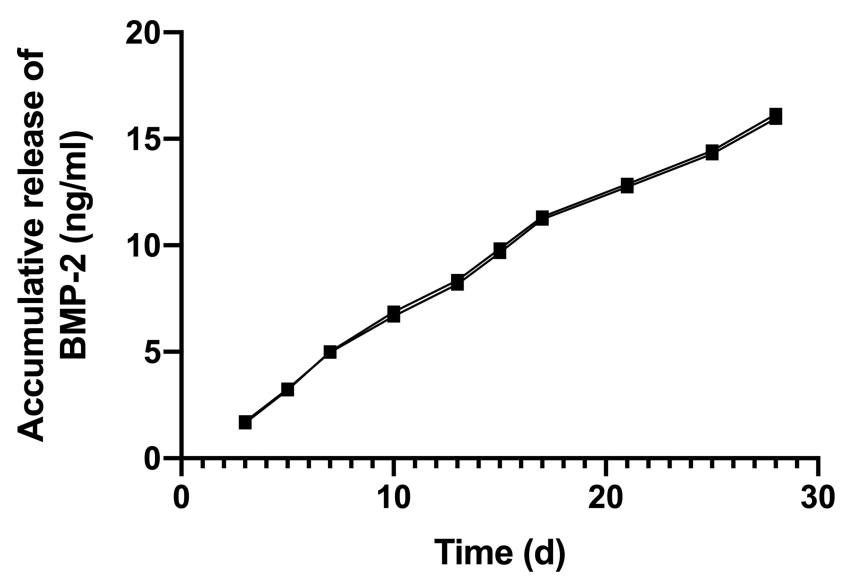

Figure 4 Accumulative release of BMP-2 under physiological condition (PBS, $37^{\circ}$ C). During the 27 days of release study in vitro, it was observed that approximately $96.78 \%$ of the immobilized BMP-2 was retained on the fibers, and about 3.2\% BMP2 continued to be released for 27 days.

$B M P 2$ in the DPB group was higher than that in the DP and control groups after 14 days of incubation (Figure 7C). There was no significant difference between the three groups for the expression of COL1 (Figure 7D).

\section{Electrospun Fibers Promoted Osteogenesis in vivo}

To detect for osteogenesis induction in vivo, we implanted the material into the acetabular defects of animal models and assessed the tissue regeneration at 24 weeks postoperatively. In general observation (Figure 8A-R), at 24 weeks after surgery, the PELA electrospun fiber was completely degraded, only surgical sutures and anchors were found. Most of the acetabular defects had been filled with new tissues. Sixteen acetabular defects were fully filled, and two defects were not filled after implant detachment. The color of the implants was redder than the normal surrounding tissues, with most of them being pale pink.

Histologically, H\&E staining showed that many spindle-shaped fibroblast cells were found in the gluteus medius tendon (T) group (Figure 9A1-A3). Fibroblast cells and oval-shaped chondrocytes were observed in the DP group (Figure 9B1-B3). In the DPB group, we observed a large number of chondrocytes and some fibroblast cells (Figure 9C1-C3).
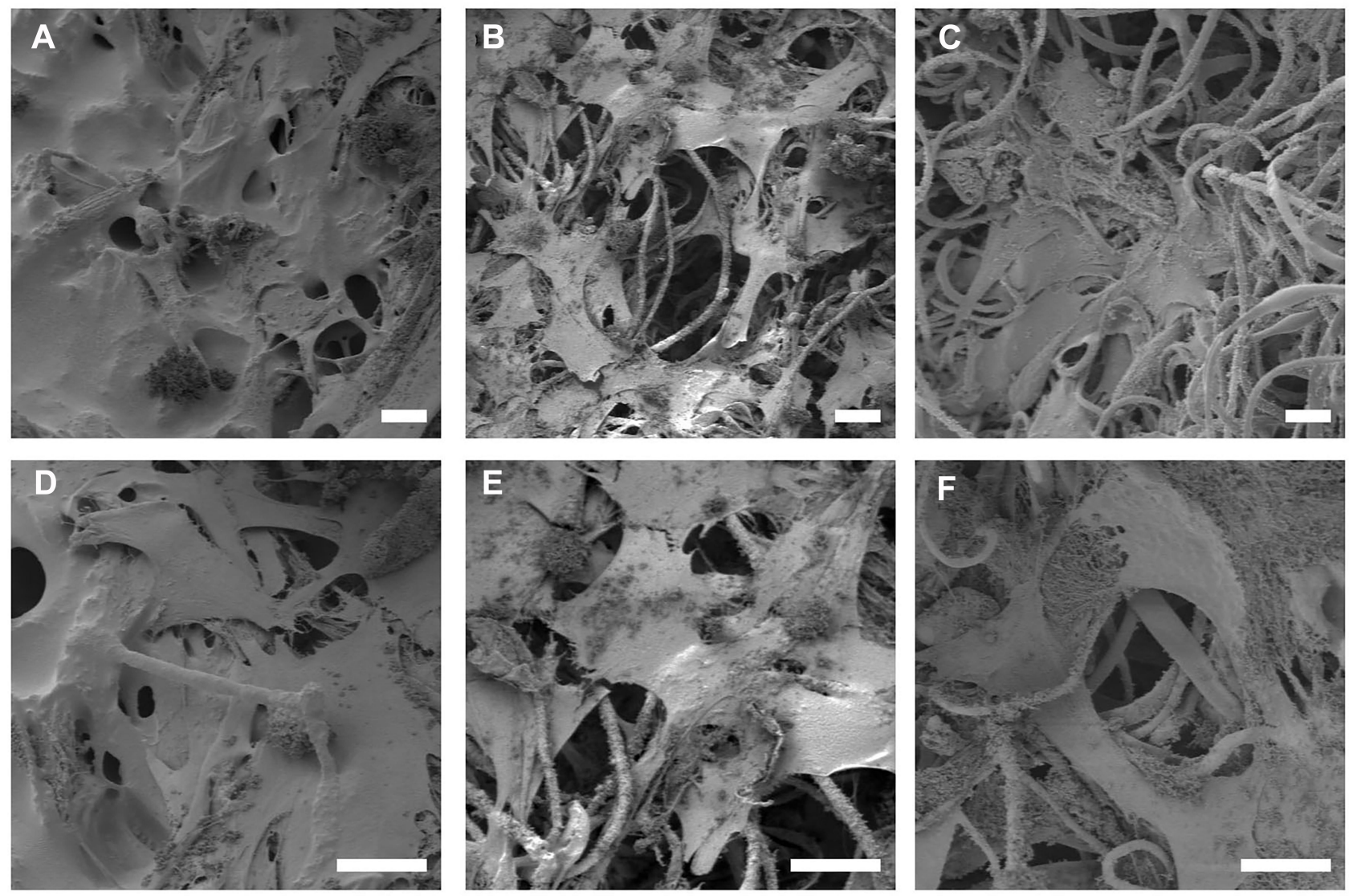

Figure 5 Morphology of hMSCs cultured on scaffolds. (A and D) P group; (B and E) DP group; $(\mathbf{C}$ and $\mathbf{F})$ DPB group. Scale bar $=10 \mu \mathrm{m}$. There was stable cell attachment and growth on the DP group at 7 days; significantly more hMSCs were recruited onto the DP group than onto the $\mathrm{P}$ group. 

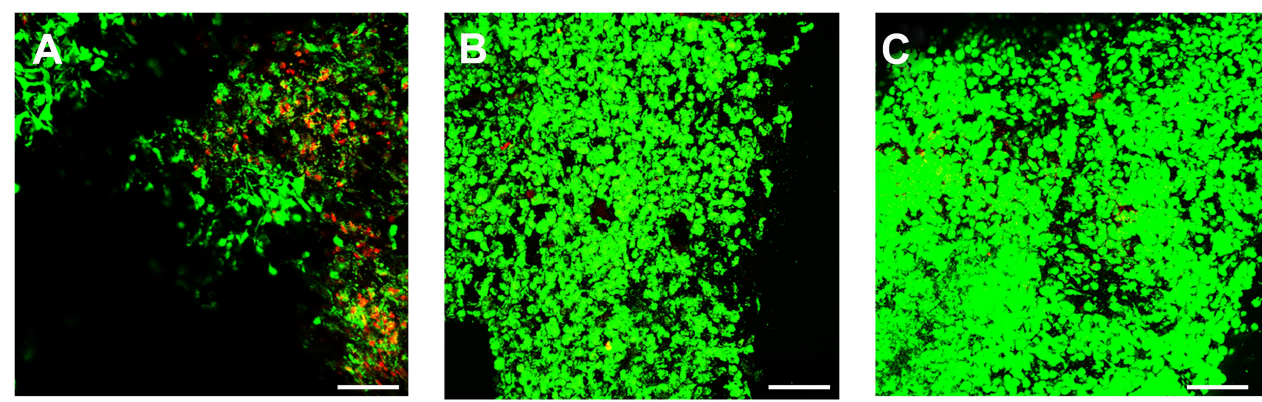

D

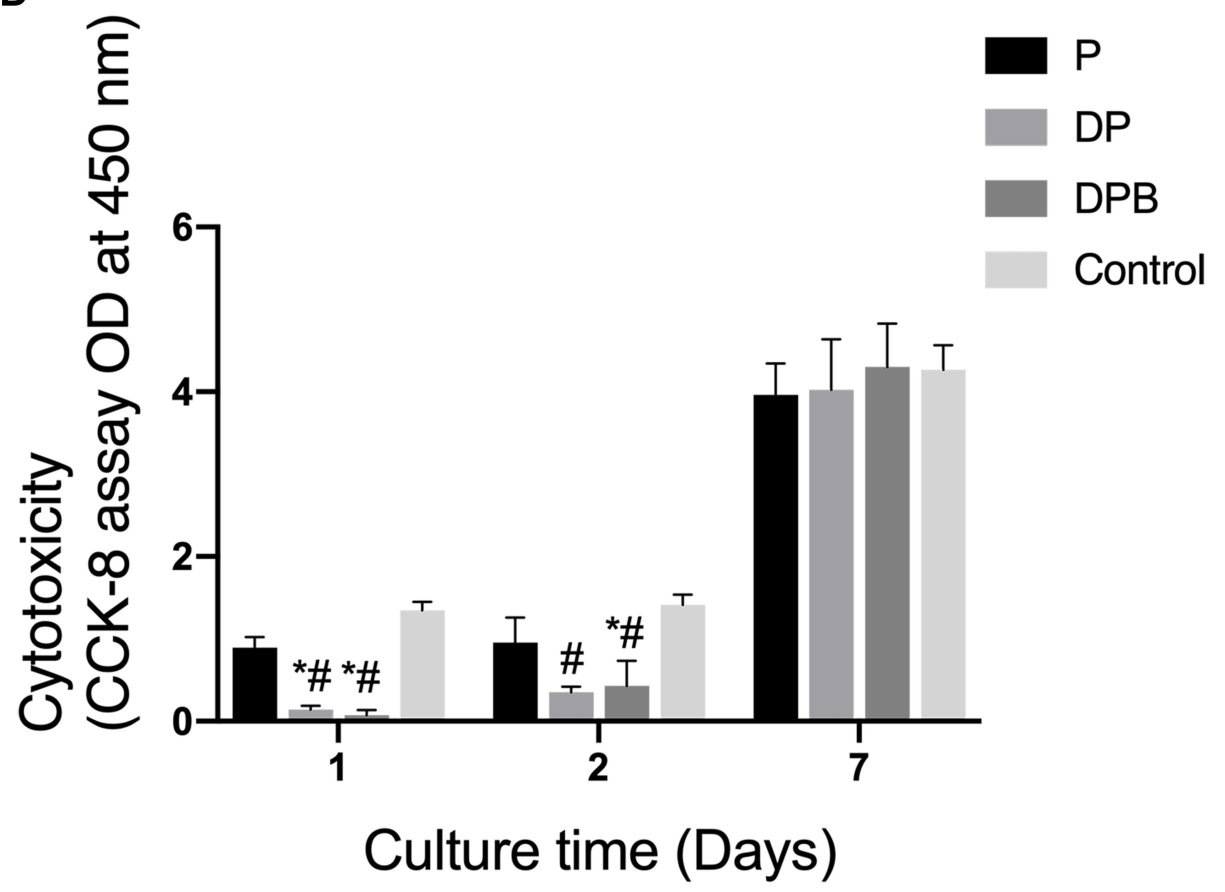

Figure 6 Biocompatibility of electrospun fibrous scaffolds. (A-C) Confocal images of hMSCs, seeded on P, DP, and DPB scaffolds after 7 days; (D) Cytotoxicity of the scaffolds in vitro, scale bar $=100 \mu \mathrm{m}$. ( $n=5$, *compared with the control group, $\mathrm{P}<0.05$; \# compared with the $\mathrm{P}$ group, $\mathrm{P}<0.05)$.

To analyze the formation of new bone tissues, sections were further stained with Goldner's trichrome, which showed that chondrocytes and fibroblast cells were found inside the implants of the DP group, while no bone tissue was found (Figure 10A1-A3). There were new bone tissue and many chondrocytes in the DPB group (Figure 10B1-B3), which confirmed that the use of DPB could lead to new bone tissue formation.

\section{Discussion}

Minimally invasive treatment of DDH had received much attention in recent years, and the development of hip arthroscopy provided new directions for treatment. Experiments on the hip joint complicated, which has limited research into hip disease. In this study, we reconstructed the acetabular defects by wrapping the gluteus medius tendon with an electrospun fiber. The implants can be easily shaped using arthroscopy instruments, making it easier to achieve acetabular capping, which might have great value for future clinical applications. The polydopamine-coated electrospun fibers had larger diameters than the non-coated fibers. Previous studies also used polydopamine to cross-link affinity peptides in nanofibers, and coated fibers were thickened, further illustrating that polydopamine was successfully cross-linked, with no significant effect on the attachment and growth of cells. ${ }^{30}$

The simulated release process in vitro confirmed that BMP-2 can achieve long-term release while maintaining its activity. The in vitro osteogenesis experiments showed that the released BMP-2 could promote osteogenic differentiation compared with that of the control group and BMP-2-free group. The expression of osteogenic genes was significantly different among the groups. The results of the in vivo experiment showed that bone tissue formed 

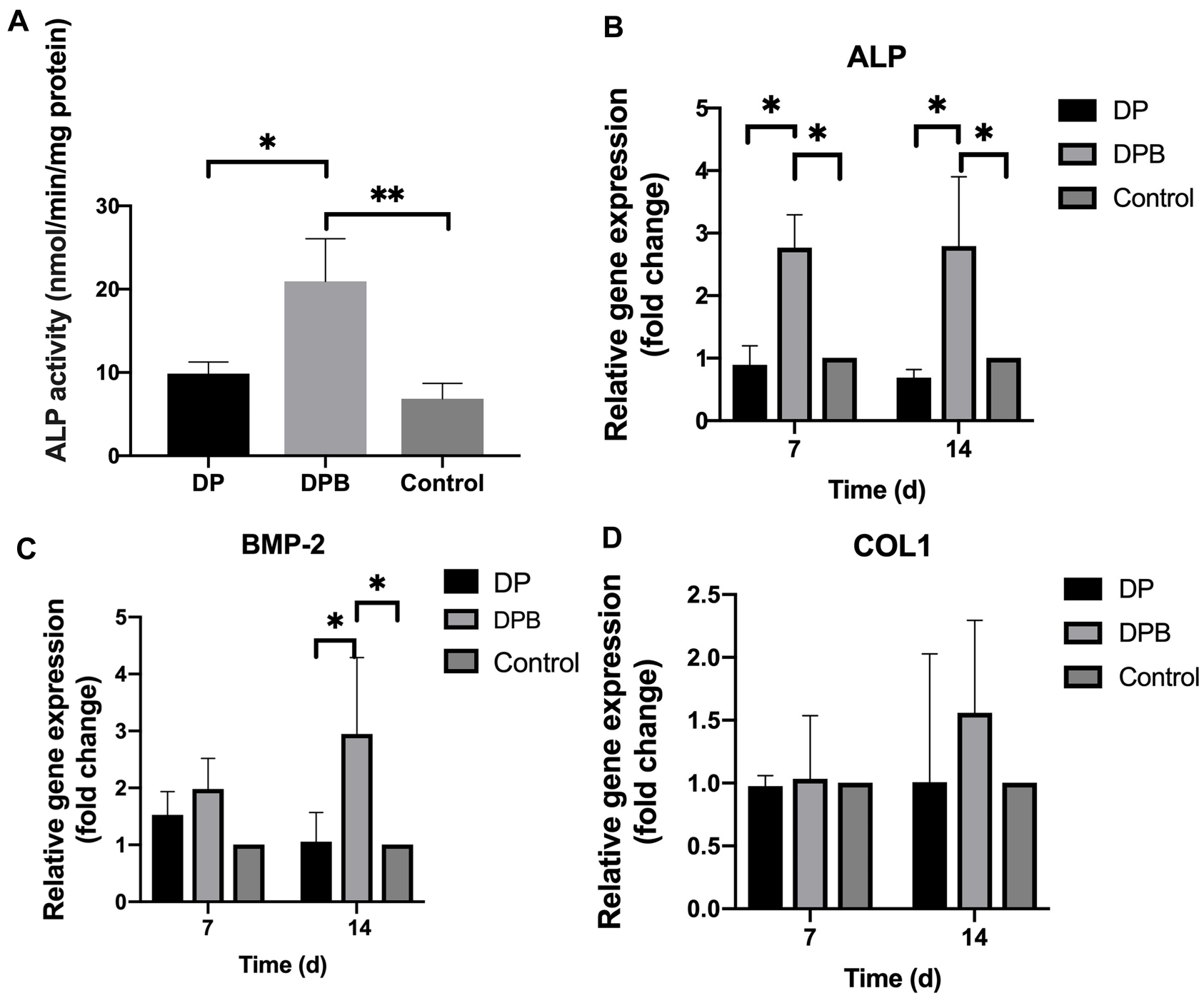

Figure 7 Osteogenic differentiation of hMSCs on scaffolds. (A) ALP activity of hMSCs on the P, DP, and DPB groups for 7 days; (B) ALP gene relative expression on different scaffolds at 7 and I 4 days; (C) BMP2 relative gene expression on different scaffolds at 7 and I4 days; (D) COLI gene relative expression on different scaffolds at 7 and I4 days. $\left(*_{p}<0.05,{ }^{* *} \mathrm{p}<0.01\right)$.

in the DPB group, in addition to a large number of chondrocytes and some fibroblasts. The tissue of the control group and the DP group showed many fibroblasts with few chondrocytes. These results indicated that the material not only had good biocompatibility, but also released BMP-2 and retained its activity, and promoted tissue healing and partial acetabular osteogenic differentiation.

The release of BMP-2 corresponded to the kinetic characteristics, which showed that a suitable carrier was important. Kim et $\mathrm{al}^{31}$ cross-linked BMP-2 on hydroxylapatite and PCL scaffolds to repair rabbit skull defects; however, the PCL polymer was difficult to degrade, which affected the formation of new bone, and the material was not suitable for arthroscopic surgery. Encapsulation of BMP-2 in microspheres is a common method of delivery. Yilgor et $\mathrm{al}^{32}$ attempted to encapsulate BMP-2 and BMP-7 in a microcapsule and then bind it to chitosan electrospun fibers. The strong induction of osteogenic differentiation of BMSCs provided a new direction for the release of growth factors to promote bone regeneration. However, the process of preparing scaffolds was more complicated, costly, and lacked in vivo experiments.

In the current study, we used electrospun fibers as a carrier for BMP-2. Firstly, electrospun fiber overcame the difficulty of the rapid degradation of BMP-2 when used directly in vivo. If injected directly, the factor may diffuse into the blood and become inactivated rapidly. More importantly, considering the operation of arthroscopic surgery, the implant can be shaped by surgical instruments to repair the defected acetabulum. In the present study, the electrospun scaffolds not only acted as a release carrier for BMP-2, but 

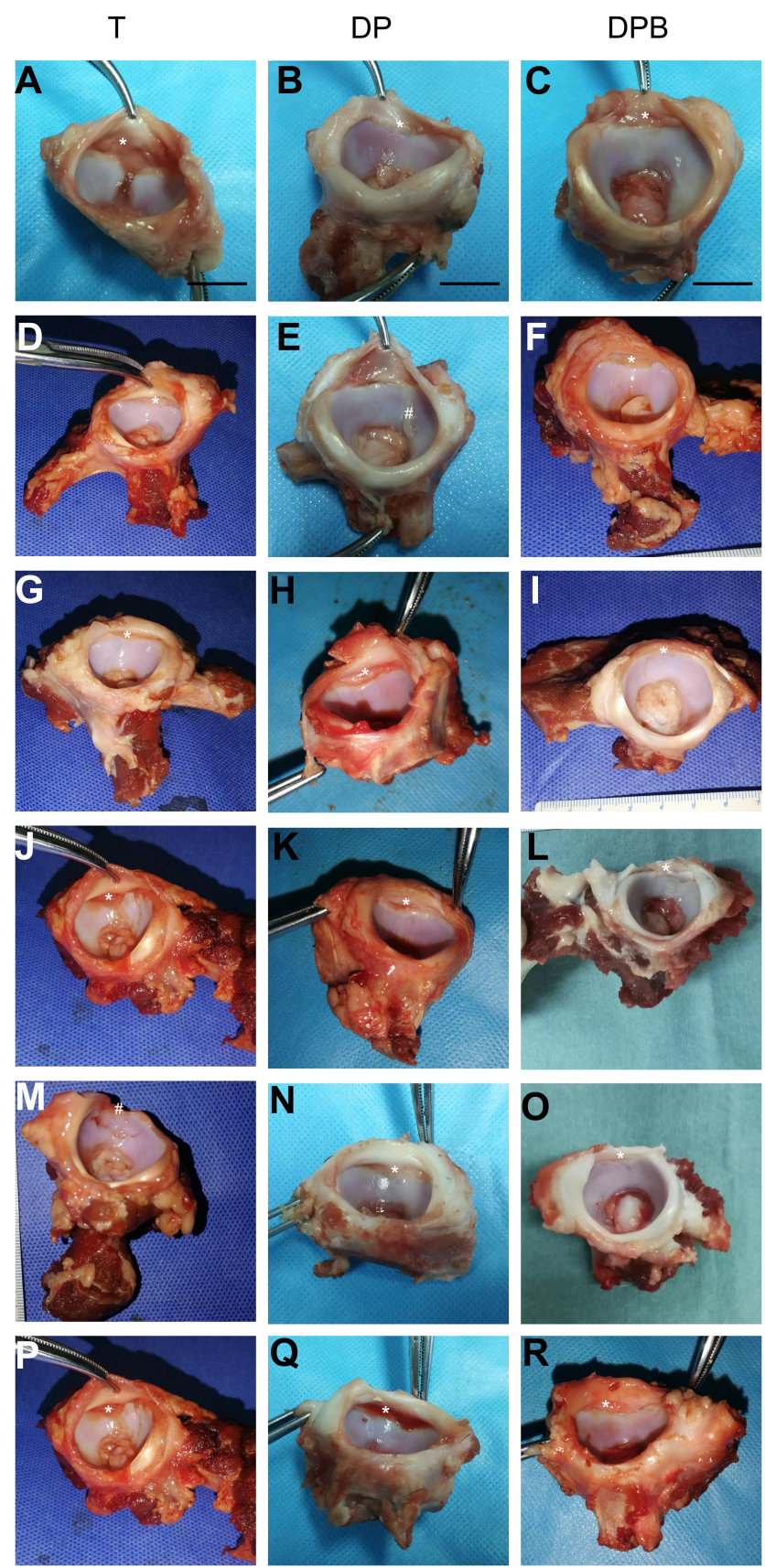

Figure 8 Macroscopic observation of the implants at 24 weeks. (A-P) Macroscopic view of the tendon group; (B-Q) Macroscopic view of the DP group; (C-R) Macroscopic view of the DPB group. *Indicates that the implants filled the defects; \# indicates that the implants became detached, scale bar $=2 \mathrm{~cm}$.

were also used to wrap the tendon and form a tissue engineering scaffold. The PELA electrospun fiber completely degraded in vivo, with a simple production process and no toxicity, and showed good cell adhesion, which was superior to previously reported electrospun materials. ${ }^{33-35}$

Previously, BMP-2 had been combined with dopamine for osteogenic differentiation. However, these studies focused on critical bone defects, and most were small animal studies. Cho et $\mathrm{al}^{26}$ implanted BMP-2 immobilized electrospun fiber into skull defects of mice. The result showed that the amount of new bone formation was high compared with that in the control group and the electrospun fiber only group; therefore, it may represent an effective method to induce osteogenesis. A similar method is also used to crosslink other factors, such as affinity peptides. $^{29}$ Dopamine increased the hydrophilicity of the material and surface area, and improved cell adhesion and survival. However, it should be noted that the immobilization rate of growth factors was high, such that a large number of factors remain on the material without slowrelease, which might be costly; therefore, more effective immobilization methods should be studied later.

In the current study, we confirmed that BMP-2/PELA can promote osteogenesis. In vivo experiments for 6 months showed complete healing of the acetabular defects, with a large number of chondrocytes, some osteoblasts, and incomplete bone formation. These results might be explained if the dose of BMP-2 in the in vivo experiment was insufficient. A lack of previous studies meant that we decided to add $1 \mu \mathrm{g}$ of BMP-2 to the implant, based on more distantly related studies. Factor inactivation might occur during experimental preparation and surgery, making the implants not fully osteogenic. Secondly, BMP-2, as a member of the TGF- $\beta$ superfamily, can induce MSCs to differentiate into chondrocytes. Studies have found that ${ }^{36}$ BMP-2 regulates the cell cycle of chondrocytes and is involved in the regulation of stem cell differentiation. Many factors determine the osteogenic differentiation of MSCs, such as cell microenvironment during growth, and the regulation of this process by growth factors is still under research. We hypothesized that the dose of BMP-2 is closely related to the direction of MSC differentiation. Another explanation is that BMP-2 also induced the cells to progress to the stage of chondrogenesis before osteogenesis. To test this hypothesis, further research is needed. Previously, our laboratory tested the tensile features of labra and implants of tendons. ${ }^{37}$ The acetabulum labrum and tendon implants had similar tensile strengths at 24 weeks after surgery. The result indicated that the implants can provide effective support to resist the compression and tensile forces produced during hip joint motion. We will further analyze the biomechanical characteristics of tissue for the hip in a future study.

Previous research only involved autologous tissue repair, which cannot complete osteogenic differentiation at the acetabular defect and cannot restore the biomechanical function. 

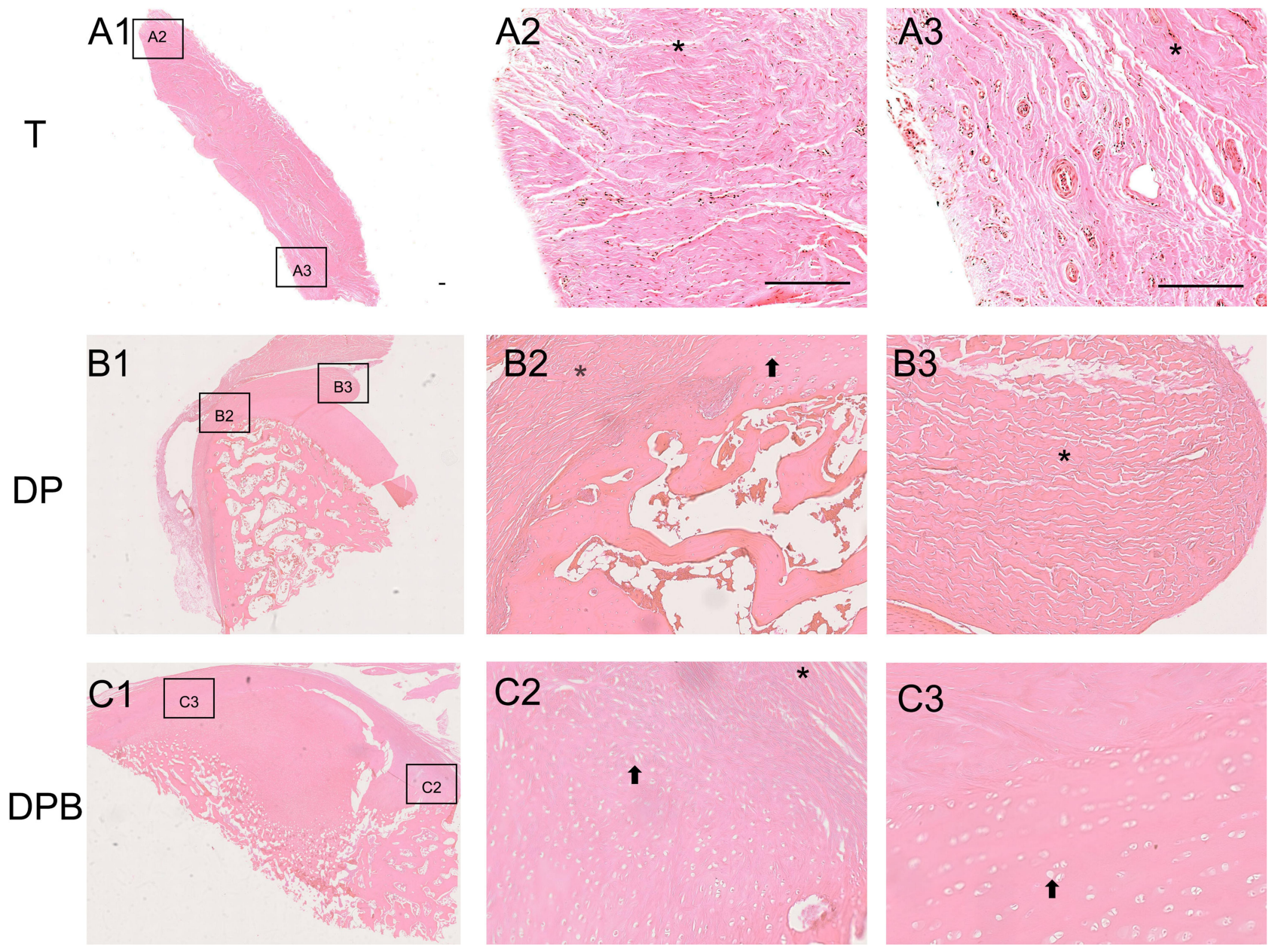

Figure 9 H\&E stained images of implants at 24 weeks. (A) T group; (B) DP group; (C) DPB group. Fibroblasts (*) were observed in the implants; chondrocytes (arrow) were found in the DP and DPB groups, scale bar $=200 \mu \mathrm{m}$.

The novelty and advantages of the present study are: First, the electrospun fiber is simple and cheap to manufacture, and has been used widely in research. It also avoids the shortcomings of painful bone extraction area and limited bone at the extraction area. Second, cartilage and bone tissue was formed in the acetabulum, and acetabulum capping was more complete. Third, the integration of medicine and engineering was achieved, such that the research results represent a breakthrough in the field of minimally invasive treatment for DDH. It is expected that the basic research results will be transformed for use in clinical therapy in the future.

The research has broad application prospects. It can be used in the field of osteogenesis; the material can be shaped to repair damaged tissue. In addition, polydopamine-coated electrospun fibers can be used as a drug delivery system, including the sustained release of the drug, which can be widely used to treat diseases. Furthermore, it can also be used in gene therapy to achieve local gene transduction.
There were some limitations to the study. First, we did not measure the tensile strength of the electrospun scaffolds. The electrospun scaffold will be completely degraded in the body, acting only as a carrier of BMP-2, with tendons and wireanchors providing the main mechanical strength. Therefore, we did not consider it necessary to measure its tensile strength; however, we will supplement this data in subsequent studies. Second, the biomechanical characteristics and size of the pig acetabulums are different from those of humans; therefore, it was not sufficient to only determine the reconstruction result of the acetabulum. In addition, there was only one time point in the in vivo experiment. Considering that a pre-experiment found that the implants healed incompletely at 12 weeks, the duration of the animal experiment might be extended in follow-up studies. In addition, the experimental group did not contain different concentrations of BMP-2. Considering the cost of the applied factors and the surgical operations in the animal experiments, 

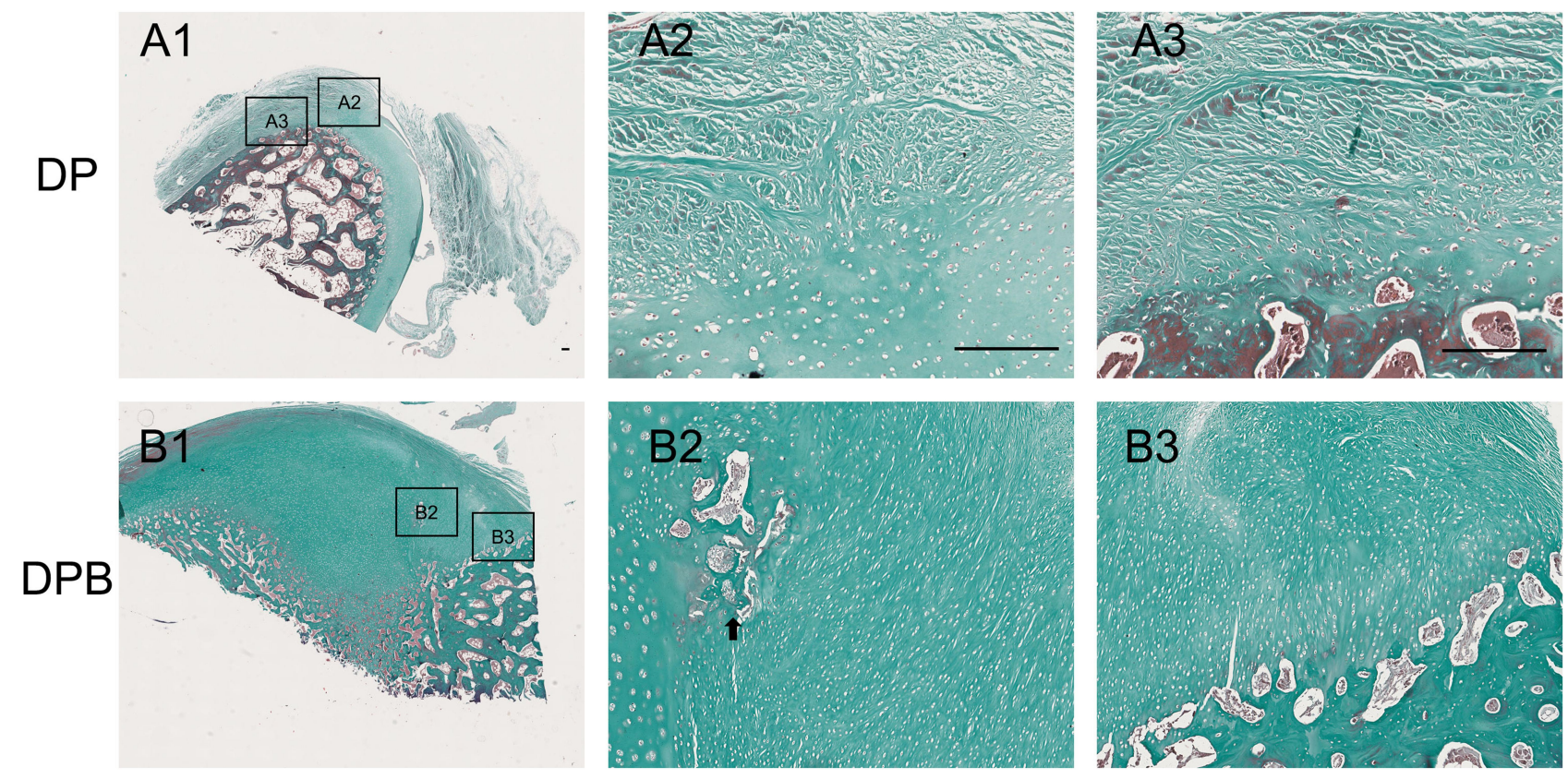

Figure 10 Goldner's trichrome stained images of implants at 24 weeks. $($ A) DP group; $($ B) DPB group. New bone tissue (arrow) was found in the DPB group, scale bar = $200 \mu \mathrm{m}$.

we only performed the in vivo experiments with a single concentration of BMP-2, and further experiments might be needed to determine the most effective dose of BMP-2 in vivo.

\section{Conclusion}

In this study, we developed a polydopamine-coated PELA electrospun scaffold containing BMP-2 that was used to repair the acetabular defects. The PELA electrospun fibrous scaffold is a good sustained-release carrier, which could not only induce implant differentiation into cartilage and bone, but was also completely degraded without toxicity. The acetabulum labrum and tendon implants had similar tensile strengths at 24 weeks after surgery. In future, it is expected that the electrospun scaffold will be further optimized, such as applying hydroxyapatite to increase its osteogenic effect, and improving the efficiency of growth factor release.

\section{Acknowledgments}

We thank Xiaoqing $\mathrm{Hu}$, Xin $\mathrm{Fu}$, Jiying Zhang, and Xiaoning Duan for their technical help. This work was financially supported by the National Natural Science Foundation of China (Grant No. 81672182).

\section{Disclosure}

The authors report no conflicts of interest associated with this work.

\section{References}

1. Wyles CC, Heidenreich MJ, Jeng J, Larson DR, Trousdale RT, Sierra RJ. The John Charnley Award: redefining the Natural history of osteoarthritis in patients with hip dysplasia and impingement. Clin Orthop Relat Res. 2017;475(2):336-350. doi:10.1007/s11999-0164815-2

2. Morita D, Hasegawa Y, Seki T, et al. A possible new radiographic predictor of progression of osteoarthritis in developmental dysplasia of the hip: the center gap. Clin Orthop Relat Res. 2018;476 (11):2157-2166. doi:10.1097/corr.0000000000000458

3. De Hundt M, Vlemmix F, Bais J, et al. Risk factors for developmental dysplasia of the hip: a meta-analysis. Eur J Obstet Gynecol Reprod Biol. 2012;165(1):8-17. doi:10.1016/j.ejogrb.2012.06.030

4. Stein-Zamir C, Volovik I, Rishpon S, Sabi R. Developmental dysplasia of the hip: risk markers, clinical screening and outcome. Pediatr Int. 2008;50(3):341-345. doi:10.1111/j.1442-200X.2008.02575.x

5. Pollet V, Percy V, Prior HJ. Relative risk and incidence for developmental dysplasia of the hip. $J$ Pediatr. 2017;181:202-207. doi:10.1016/j.jpeds.2016.10.017

6. Trousdale RT, Ekkernkamp A, Ganz R, Wallrichs SL. Periacetabular and intertrochanteric osteotomy for the treatment of osteoarthrosis in dysplastic hips. JBJS. 1995;77(1):73-85. doi:10.2106/00004623199501000-00010

7. Zaltz I, Baca G, Kim Y-J, et al. Complications associated with the periacetabular osteotomy: a prospective multicenter study. $J$ Bone Joint Surg Am. 2014;96(23):1967-1974. doi:10.2106/JBJS.N.00113

8. Kosuge D, Yamada N, Azegami S, Achan P, Ramachandran M. Management of developmental dysplasia of the hip in young adults: current concepts. Bone Joint J. 2013;95-b(6):732-737. doi:10.1302/ 0301-620x.95b6.31286

9. Huang YZ, Xie HQ, Silini A, et al. Mesenchymal stem/progenitor cells derived from articular cartilage, synovial membrane and synovial fluid for cartilage regeneration: current status and future perspectives. Stem Cell Rev Rep. 2017;13(5):575-586. doi:10.1007/ s12015-017-9753-1 
10. Cui D, Li H, Xu X, et al. Mesenchymal stem cells for cartilage regeneration of TMJ osteoarthritis. Stem Cells Int. 2017;2017:5979741. doi:10.1155/2017/5979741

11. Wang J, Liu S, Li J, Zhao S, Yi Z. Roles for miRNAs in osteogenic differentiation of bone marrow mesenchymal stem cells. Stem Cell Res Ther. 2019;10(1):197. doi:10.1186/s13287-019-1309-7

12. Bauge C, Girard N, Lhuissier E, Bazille C, Boumediene K. Regulation and role of TGFbeta signaling pathway in aging and osteoarthritis joints. Aging Dis. 2014;5(6):394-405. doi:10.14336/ AD.2014.0500394

13. Carreira AC, Zambuzzi WF, Rossi MC, Astorino Filho R, Sogayar MC, Granjeiro JM. Bone morphogenetic proteins: promising molecules for bone healing, bioengineering, and regenerative medicine. Vitam Horm. 2015;99:293-322. doi:10.1016/bs.vh.2015. 06.002

14. Elias E, Nasser Z, Winegan L, Verla T, Omeis I. Bone morphogenetic protein usage in anterior lumbar interbody fusion: what else can go wrong? World Neurosurg. 2018;111:55-59. doi:10.1016/j. wneu.2017.11.182

15. Fu R, Selph S, McDonagh M, et al. Effectiveness and harms of recombinant human bone morphogenetic protein-2 in spine fusion: a systematic review and meta-analysis. Ann Intern Med. 2013;158 (12):890-902. doi:10.7326/0003-4819-158-12-201306180-00006

16. Chen W, Chen S, Morsi Y, et al. Superabsorbent 3D Scaffold based on electrospun nanofibers for cartilage tissue engineering. ACS Appl Mater Interfaces. 2016;8(37):24415-24425. doi:10.1021/acsami.6b06825

17. Salami MA, Kaveian F, Rafienia M, Saber-Samandari S, Khandan A, Naeimi M. Electrospun polycaprolactone/ lignin-based nanocomposite as a novel tissue scaffold for biomedical applications. $J$ Med Signals Sens. 2017;7(4):228-238. doi:10.4103/jmss.JMSS_11_17

18. Feng X, Li J, Zhang X, Liu T, Ding J, Chen X. Electrospun polymer micro/nanofibers as pharmaceutical repositories for healthcare. $J$ Control Release. 2019;302:19-41. doi:10.1016/j.jconrel.2019. 03.020

19. Kutikov AB, Song J. An amphiphilic degradable polymer/hydroxyapatite composite with enhanced handling characteristics promotes osteogenic gene expression in bone marrow stromal cells. Acta Biomater. 2013;9(9):8354-8364. doi:10.1016/j.actbio.2013.06.013

20. Kutikov AB, Skelly JD, Ayers DC, Song J. Templated repair of long bone defects in rats with bioactive spiral-wrapped electrospun amphiphilic polymer/hydroxyapatite scaffolds. ACS Appl Mater Interfaces. 2015;7(8):4890-4901. doi:10.1021/am508984y

21. Liu S, Hu C, Li F, Li X-J, Cui W, Fan C. Prevention of peritendinous adhesions with electrospun ibuprofen-loaded poly(L-lactic acid)-polyethylene glycol fibrous membranes. Tissue Eng Part A. 2013;19(3-4):529-537. doi:10.1089/ten.TEA.2012.0208

22. Zhou J, Guo X, Zheng Q, Wu Y, Cui F, Wu B. Improving osteogenesis of three-dimensional porous scaffold based on mineralized recombinant human-like collagen via mussel-inspired polydopamine and effective immobilization of BMP-2-derived peptide. Colloids Surf B Biointerfaces. 2017;152:124-132. doi:10.1016/j.colsurfb. 2016.12.041

23. Ko E, Yang K, Shin J, Cho SW. Polydopamine-assisted osteoinductive peptide immobilization of polymer scaffolds for enhanced bone regeneration by human adipose-derived stem cells. Biomacromolecules. 2013;14(9):3202-3213. doi:10.1021/bm4008343

24. Perikamana SK, Lee J, Ahmad T, et al. Effects of immobilized BMP-2 and nanofiber morphology on in vitro osteogenic differentiation of hMSCs and in vivo collagen assembly of regenerated bone. ACS Appl Mater Interfaces. 2015;7(16):8798-8808. doi:10.1021/ acsami.5b01340
25. Man Z, Yin L, Shao Z, et al. The effects of co-delivery of BMSC-affinity peptide and rhTGF-betal from coaxial electrospun scaffolds on chondrogenic differentiation. Biomaterials. 2014;35(19):5250-5260. doi:10.1016/j.biomaterials.2014.03. 031

26. Cho HJ, Perikamana SK, Lee JH, et al. Effective immobilization of BMP-2 mediated by polydopamine coating on biodegradable nanofibers for enhanced in vivo bone formation. ACS Appl Mater Interfaces. 2014;6(14):11225-11235. doi:10.1021/am501 $391 z$

27. Su Y, Su Q, Liu W, et al. Controlled release of bone morphogenetic protein 2 and dexamethasone loaded in core-shell PLLACL-collagen fibers for use in bone tissue engineering. Acta Biomater. 2012;8 (2):763-771. doi:10.1016/j.actbio.2011.11.002

28. Lee J, Perikamana SK, Ahmad T, et al. Controlled retention of BMP-2-derived peptide on nanofibers based on mussel-inspired adhesion for bone formation. Tissue Eng Part A. 2017;23(7-8):323-334. doi:10.1089/ten.TEA.2016.0363

29. Lee YJ, Lee JH, Cho HJ, Kim HK, Yoon TR, Shin H. Electrospun fibers immobilized with bone forming peptide-1 derived from BMP7 for guided bone regeneration. Biomaterials. 2013;34(21):5059-5069. doi:10.1016/j.biomaterials.2013.03.051

30. Ye K, Liu D, Kuang H, et al. Three-dimensional electrospun nanofibrous scaffolds displaying bone morphogenetic protein-2-derived peptides for the promotion of osteogenic differentiation of stem cells and bone regeneration. J Colloid Interface Sci. 2019;534:625-636. doi:10.1016/j.jcis.2018.09.071

31. Kim BS, Yang SS, Kim CS. Incorporation of BMP-2 nanoparticles on the surface of a 3D-printed hydroxyapatite scaffold using an epsilon-polycaprolactone polymer emulsion coating method for bone tissue engineering. Colloids Surf $B$ Biointerfaces. 2018;170:421-429. doi:10.1016/j.colsurfb.2018.06.043

32. Yilgor P, Sousa RA, Reis RL, Hasirci N, Hasirci V. Effect of scaffold architecture and BMP-2/BMP-7 delivery on in vitro bone regeneration. J Mater Sci Mater Med. 2010;21(11):2999-3008. doi:10.1007/s10856-010-4150-1

33. Kim H, Che L, Ha Y, Ryu W. Mechanically-reinforced electrospun composite silk fibroin nanofibers containing hydroxyapatite nanoparticles. Mater Sci Eng C Mater Biol Appl. 2014;40:324-335. doi:10.1016/j.msec.2014.04.012

34. Shao Z, Zhang X, Pi Y, et al. Polycaprolactone electrospun mesh conjugated with an MSC affinity peptide for MSC homing in vivo. Biomaterials. 2012;33(12):3375-3387. doi:10.1016/j.biomaterials. 2012.01.033

35. Li C, Vepari C, Jin HJ, Kim HJ, Kaplan DL. Electrospun silk-BMP-2 scaffolds for bone tissue engineering. Biomaterials. 2006;27(16):3115-3124. doi:10.1016/j.biomaterials.2006.01.022

36. Salazar VS, Gamer LW, Rosen V. BMP signalling in skeletal development, disease and repair. Nat Rev Endocrinol. 2016;12 (4):203-221. doi:10.1038/nrendo.2016.12

37. Shi Y, Chen L, Xu Y, et al. Acetabular labral reconstruction using autografts reduces osteoarthritis development compared with labral resection in a porcine model. Am $J$ Transl Res. 2019;11 (4):2484-2495.

38. Servier Medical Art. Available from: https://smart.servier.com/. Accessed August 18, 2020. 


\section{Publish your work in this journal}

The International Journal of Nanomedicine is an international, peerreviewed journal focusing on the application of nanotechnology in diagnostics, therapeutics, and drug delivery systems throughout the biomedical field. This journal is indexed on PubMed Central, MedLine, CAS, SciSearch ${ }^{\mathbb{B}}$, Current Contents ${ }^{\mathbb{B}} /$ Clinical Medicine, $^{2}$
Journal Citation Reports/Science Edition, EMBase, Scopus and the Elsevier Bibliographic databases. The manuscript management system is completely online and includes a very quick and fair peer-review system, which is all easy to use. Visit http://www.dovepress.com/ testimonials.php to read real quotes from published authors.

Submit your manuscript here: https://www.dovepress.com/international-journal-of-nanomedicine-journal 